\title{
Investigating the use of spatial reasoning strategies in geometric problem solving
}

\author{
Jeffrey Buckley $^{1}$ (D) Niall Seery $^{1,2}$ (D) Donal Canty $^{3}$ (D)
}

Accepted: 14 March 2018 / Published online: 20 March 2018

(C) The Author(s) 2018

\begin{abstract}
A core aim of contemporary science, technology, engineering, and mathematics (STEM) education is the development of robust problem-solving skills. This can be achieved by fostering both discipline knowledge expertise and general cognitive abilities associated with problem solving. One of the most important cognitive abilities in STEM education is spatial ability however understandings of how students use this ability in practice are currently underdeveloped. Therefore, this study aimed to investigate how levels of spatial ability impacted both performance and approaches to problem solving. In the context of graphical education, selected due to its significant overlap with technological, mathematical and engineering knowledge, a repeated cross-sectional study design was implemented to gather longitudinal data of student approaches to problem solving. A battery of psychometric tests of spatial ability was administered to two cohorts and problem solving was examined through a variety of graphical problems. The findings illustrate a relationship between attaining higher levels of spatial ability and performance. Participants with lower levels of spatial ability evidenced the utilisation of models to a greater extend with a particular emphasis on models with the capacity to alleviate the need for spatial reasoning.
\end{abstract}

Keywords Spatial ability · Problem solving $\cdot$ STEM education $\cdot$ Graphical education

\section{Introduction}

The development of robust problem-solving skills is among one of the most important focusses of contemporary education (Dow 2006). Problem solving is a fundamental human cognitive process (Wang and Chiew 2010) which has been identified as one of the basic

Jeffrey Buckley

jbuckley@kth.se

1 KTH Royal Institute of Technology, Stockholm, Sweden

2 Athlone Institute of Technology, Westmeath, Ireland

3 University of Limerick, Limerick, Ireland 
life functions of natural intelligence in the brain (Wang et al. 2006). Additionally, the use of problem solving in education can have a significant impact on student learning (Dochy et al. 2003; Hmelo-silver 2004; Hung et al. 2008; Loyens et al. 2011; Savery and Duffy 2001; Williams et al. 2008). The need to develop problem-solving competencies is further accentuated by the constantly evolving nature of society in which students need to be equipped to negotiate. As society has advanced into the conceptual age (Pink 2005) where ubiquitous access to pertinent information has become a reality, education systems need to respond by facilitating the development of cognitive flexibility and supporting fluidity in problem solving and reasoning.

In science, technology, engineering and mathematics (STEM) education in particular, problem solving in a core pedagogical approach adopted to facilitate academic achievement (Barrows 1996; Gallagher et al. 1995; Lou et al. 2011; Perrenet et al. 2000; Williams and Williams 1997; Williams et al. 2008). This makes understanding the core processes which allow students to engage in problem solving, and which are enhanced through problem solving, of paramount importance for increasing the efficacy of pedagogical practices. In STEM education, spatial ability has been shown to correlate with academic performance in multiple sub-disciplines including biology (Rochford 1985; Russell-Gebbett 1985), chemistry (Small and Morton 1983; Wu and Shah 2004), physics (Kozhevnikov et al. 2007), mathematics (Cheng and Mix 2014; Cromley et al. 2017; Pittalis and Christou 2010; Sorby et al. 2013), computer programming (Jones and Burnett 2008), design (Lin 2016), engineering graphics (Marunic and Glazar 2013), geometry (Suzuki et al. 1990), and engineering (Alias et al. 2002; Sorby 2009). Furthermore, a number of longitudinal studies examining the association between spatial ability and STEM across multiple subdisciplines provide evidence which categorically demonstrates its importance (Shea et al. 2001; Wai et al. 2009; Webb et al. 2007). Based on this evidence it is clear that spatial ability is a particular ability which supports problem solving in many STEM education disciplines.

\section{Spatial ability and STEM education}

While the association between spatial ability and STEM education has been categorically determined, the causal relationship is still unclear (Ramey and Uttal 2017). In particular, there is a need to examine more explicitly how students utilise spatial reasoning strategies in STEM education to identify why this particular cognitive ability is so beneficial. One approach to investigating the role of spatial ability in STEM education is to explore this relationship relative to discipline expertise. Uttal and Cohen (2012) noted that there is no upper limit on the relationship between STEM and spatial ability. Additionally, at all levels of expertise there is strong relationship between spatial ability and STEM performance. However, the evidence for a relationship between spatial ability and STEM performance is weaker and less consistent for STEM experts. For example, whether expert geologists succeed or fail on an authentic geology task seems to have little to do with their level of spatial ability (Hambrick et al. 2012). Stieff (2007) identified this as being a result of spatial ability either limiting or enhancing people's ability to think spatially in the way that is appropriate for STEM thinking. Investigating the role of spatial ability between novices and experts in geoscience, Hambrick et al. (2012) found that spatial ability only significantly affected performance for participants with low geospatial knowledge whereby people with low geospatial knowledge but high levels of spatial ability performed nearly as well as participants 
with high geospatial knowledge. This resulted in Hambrick et al. (2012) formulating the 'circumvention-of-limits' hypothesis. This suggests that the acquisition of domain-specific knowledge eventually reduces or even eliminates the effects of individual differences in cognitive abilities. This hypothesis is supported by similar findings in physics (Kozhevnikov and Thornton 2006) and in chemistry (Stieff 2007). While these findings suggest that high levels of discipline specific knowledge alleviate the need for high levels of spatial ability, Miller (1984) identifies that experts are benefitted by spatial ability when coming up with new insights where available discipline specific knowledge is limited or not available. Uttal and Cohen (2012, p. 168) summarise this research suggesting that "spatial skills may be a gatekeeper or barrier for success early on in STEM majors, when (a) classes are particularly challenging, and (b) students do not yet have the necessary content knowledge that will allow them to circumvent the limits that spatial ability imposes. Early on, some students may face a Catch-22: they do not yet have the knowledge that would allow them to succeed despite relatively low spatial skills, and they can't get that knowledge without getting through the early classes where students must rely on their spatial abilities".

A second approach for investigating the explicit role of spatial ability in STEM performance can be seen in the emergence of ethnographic studies (e.g. Ramey and Uttal 2017). Defining spatial cognitive processes as 'distributed spatial sensemaking', Ramey and Uttal (2017) through ethnography identified how spatial ability is important to specific practices such as hypothesis testing and design iteration. This research shows further movement from macro level investigations which have identified the relationship between spatial ability and STEM education to more situated and context specific investigations attempting to explain causality. While investigations which examine the variable of discipline expertise and which utilise an ethnographic approach are contributing to a causal explanation, the variable of levels of spatial ability attainment also merits further exploration to fully understanding this causality. While technically correlational studies do examine levels of spatial ability, more in depth analysis is warranted to examine how students with higher levels of spatial ability engage with problem solving in comparison to students with lower levels of spatial ability. These investigations need to be contextualised in specific disciplines to allow for conclusions relative to specific cognitive processes such as in the work of Ramey and Uttal (2017). If students do not have a sufficient level of spatial ability to engage with a problem, alternative methods which are adopted could highlight specific ways by which having attained a sufficient level of spatial ability is supporting increased academic achievement.

\section{Reasoning styles pertinent to graphical reasoning}

One sub-discipline of STEM education with the potential to examine spatial ability or spatial approaches in problem solving relative to students' levels of spatial ability is graphical education (Marunic and Glazar 2013; Sorby 1999). Graphical education is a particularly auspicious subject for examining spatial ability in the context of STEM education as the knowledge base has significant overlap with other sub-disciplines of STEM such as technology, mathematics and engineering. It also aspires to develop much of the same general skills such as problem solving, critical thinking and the capacity to synthesise information. A number of correlational studies have identified a link between spatial ability and performance in graphical education (e.g. Maeda et al. 2013; Sorby 1999) suggesting the significance of spatial reasoning within graphical or geometric problem solving. Graphical 
education requires students to engage with a range of visually orientated problems. These problems implicitly suggest the adoption of a spatial reasoning strategy as they regularly include abstract visual stimuli or abstractions (Seery et al. 2011) however there is general consensus that spatial and analytical reasoning are the two primary types of reasoning involved in spatial tasks (Bodner and Guay 1997). Regarding the adoption of particular styles of reasoning, Linn and Petersen (1985) identified females as preferring analytical approaches with males preferring more holistic spatial approaches to spatial tasks. With females regularly cited as having lower levels of spatial ability to males (e.g. Sorby 2009), the selection of analytical approaches to graphical problems may allude to underdeveloped spatial skills relative to the cognitive load imposed by the problem making it ecologically irrational to select a spatial approach. In addition to the use of spatial or analytical reasoning, particularly when considering students cognitive capacities, there is a need to considering the potential of external representations in their approaches (Kirsh 2009).

\section{Modelling and the external representation of problems}

Theories of problem solving have progressed to acknowledge the role of external representations (Kirsh 2009). Larkin and Simon (1987) suggested that problem states could be partially encoded internally and partially encoded externally through the use of external representations, or 'models', of the problem. Supporting this, Chambers and Reisberg (1985) illustrated that people can explore external models differently to how they explore cognitive models of the same entity. Where internal reasoning capacities such as spatial ability are underdeveloped, students can generate an external model to provide support when problem solving. The relationship between modelling and reasoning is interconnected. While modelling can support or alleviate the need to reason, the need can also arise to reason about or while creating a model. Similar to the circumvention of limits hypothesis whereby discipline expertise can eliminate the need for general cognitive abilities, externally representing a problem or specific stimuli from within a problem can eliminate or reduce the degree of spatial reasoning required. Archer (1992, p. 7) eloquently describes a model as "anything which represents anything else for informational, experimental, evaluative or communicative purposes". Seery (2017, p. 255) develops this idea identifying modelling as "a generative process that functions as a means of making explicit or externalising the variability in thinking" noting that "directly associated with this capacity to make thinking visible (inside or outside the head), is the opportunity to critique and reason". While the creation of a model is always intentional the purpose of that model may vary and will be unique to its creator, but in all circumstances will succumb to an inquiry based agenda. Baynes (2009, p. 10) notes the situated nature of models describing a model as being "determined on the one hand by inherited deep structures in the mind and on the other hand by the content of our personal experience and culture". Koen (1985, p. 15) further emphasises this view identifying that the model does not need to be the "absolute best, but only the best relative to the society to which it applies". In the context of problem solving, the creation of the model is not necessarily representative of the solution but rather it exists as a mechanism to support the achievement of the solution. While the model has a role to play in the journey towards a solution, a second function exists in auditing. The problem solver can create a model to overcome a deficit in cognitive resources at any stage of a given problem or to appraise a solution in whole or in part for confirmation or consolation. 


\section{Research question}

Considering the need to identify the causal relationship between spatial ability and STEM performance, and the current agendas which examine this relationship relative to discipline expertise and through ethnographic approaches, this study examines problemsolving strategies relative to levels of spatial ability attainment. Specifically, the study was underpinned by three related research questions:

1. Do students with high levels of spatial ability utilise this in problem solving?

2. How do students with insufficient levels of spatial ability relative to specific graphical problem solving tasks negotiate this problem?

3. Can non-spatial approaches to graphical tasks give insight into the specific way by which spatial ability facilitates increased academic performance?

\section{Method}

\section{Approach and participants}

A repeated cross-sectional study design was implemented to gather longitudinal data of student approaches to solving graphical problems. The study was conducted across two cohorts of students in their 3rd year of an Initial Technology Teacher Education (ITTE) program while they were engaging in a graphical education module. The cohorts came from consecutive years. Cohort 1 consisted of 112 students and Cohort 2 consisted of a further 103 giving a total sample of 215 students. The students were selected as participants for this study as the graphics module they were engaging with aimed to develop reasoning styles pertinent to solving graphical problems such as spatial and analytical reasoning. It is important to acknowledge that there are many sub-disciplines within STEM and, as described earlier, spatial ability has been shown to be important in a large number of these. This cohort, while similar to many areas of STEM with respect to shared knowledge, has some unique characteristics. Graphics are often considered as a language (Baynes 2017; Danos 2017) and there is specific discipline knowledge within the subject. As a result, there is a degree of context specificity within the types of problems typically engaged with in graphical education and in the discipline specific problem solving approaches which the participants will have developed. As abstract geometries are ubiquitous within graphical education and are central to this study, this should be considered in relation to the generalisability of the results to other STEM sub-disciplines.

Within the module the students completed a battery of psychometric tests designed to measure different spatial factors and one element of the assessment architecture for the module consisted of a summative exam inclusive of a variety of graphical reasoning problems. Performance in these tasks were subsequently analysed to gain an insight into the students' reasoning styles and problem-solving approaches. As the graphical problems existed in the context of an assessment mechanism it was hypothesised that students would be incentivised to optimise their performance through the utilisation of whichever strategies they believed would be most advantageous. 


\section{Design and implementation}

Psychometric tests of spatial ability were administered to each cohort. These tests aligned with a variety of spatial factors to reflect the multi-factorial nature of spatial ability (Carroll 1993). For Cohort 1, the Purdue Spatial Visualisation Test: Visualisation of Rotations (PSVT:R) (Bodner and Guay 1997) and the Mental Cutting Test (MCT) (CEEB 1939) were selected. The PSVT:R is posited to measure the spatial relations factor or the capacity to mentally rotate complex 3-dimensional geometries and the MCT is posited to measure the visualization factor, a general factor of spatial ability describing the universal ability to mentally manipulate visual stimuli. Spatial factors are often considered to be positioned along a single speed-power or simple-to-complex continuum (Larson 1996), and both of these factors are located at the complex end of this continuum.

For Cohort 2, the PSVT:R was utilised to allow a common measure across cohorts. The MCT was replaced with an adapted Perspective Taking/Spatial Orientation Test (PTSOT) (Hegarty and Waller 2004) and the Card Rotations Test (CRT) (Ekstrom et al. 1976). The adaption to the PTSOT was necessary due to a lack of access to the original test however the adapted version was designed to utilise the exact stimulus and question design as the original test. The PTSOT measures spatial orientation, a spatial factor describing the capacity to take different perspectives in space to achieve additional egocentric perspectives of visual stimuli. The CRT measures the speeded rotation factor or the capacity to mentally rotate 2-dimensional geometries quickly. These factors were considered instead of visualization to place additional emphasis on factors associated with mental rotations. While the spatial orientation factor is located on the power end of the spatial factor continuum, speeded rotations is located at the speed end.

Each cohort received a different battery of graphical problems representative of those typically found in pedagogical and assessment practices in the subject. The battery for each cohort was differentiated only by geometric manipulation as pertinent discipline-specific knowledge requirements remained identical. The exam was designed to encourage a principles based approach to solving the problems to facilitate a degree of flexibility in the students' solutions. This battery of tasks was used as a measure of graphical problem-solving competencies within this study. All problems were included in an initial correlational analysis with the students' performance in the spatial ability tests. Following this, one problem was included for both cohorts with only a minor variation as described below which was selected for a more detailed analysis (Fig. 1). This problem was selected as it was a general task where only a basic level of domain-specific knowledge was required to interpret the task with no specific knowledge required for subsequent engagement.

The solution to the problem is divided into two parts, the creation of an auxiliary elevation and a subsequent second auxiliary in the directions of the arrows presented in the problem for Cohort 1. Each of these parts was theorised to consist of two elements, the identification of the resulting cube and the identification of the correct surface illustrations. The solution for the problem given to Cohort 1 is illustrated in Fig. 2. The only difference in problems between cohorts was that the surface illustrations representative of a dice for Cohort 1 were replaced with geometric figures for Cohort 2. 


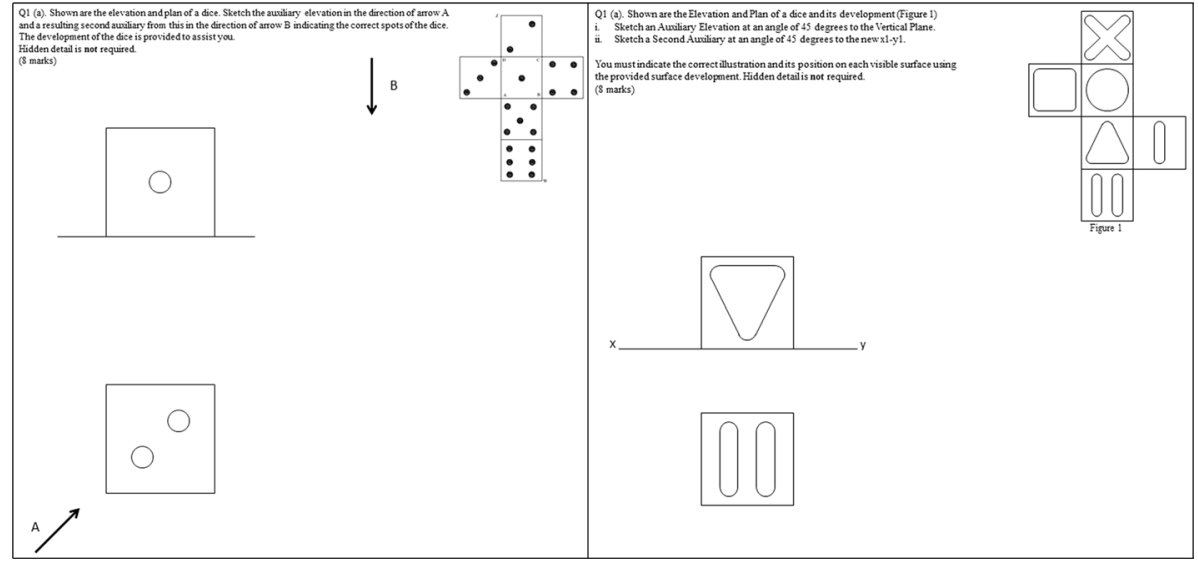

Fig. 1 Graphical problems for Cohort 1 (left) Cohort 2 (right) for the case study analysis

\section{Findings}

As the PTSOT was adapted for the purposes of this study the need arose to determine the reliability of the psychometric tests to ensure an acceptable level for consideration in further analyses. The Cronbach's Alpha values are presented in Table 1. All values were sufficiently high to support their further consideration. The score of .886 for the PTSOT suggests that the adaption of the specific questions while maintaining the design of the original test did not affect the reliability of the test. The recorded value is marginally higher than in results identified in previous studies where the goal was to ascertain the validity and reliability of the test (Hegarty and Waller 2004; Kozhevnikov and Hegarty 2001).

Subsequent to establishing the reliability of the psychometric tests, a correlational analysis was conducted between performance of the tests and performance in the graphical reasoning problems included within the summative assessments. The results of this analysis are presented in Table 2. At this stage of the investigation the cohorts were separated due to the variations in graphical problems and spatial tests they engaged with. The graphical problems are coded such that problem A1_Cube_Aux_1 refers to problem A part 1 which involves identifying the 1st auxiliary view of a cube.

There were statistically significant correlations between all spatial tests. This was expected as spatial reasoning is a second-order cognitive factor and each test was designed to measure a first-order factor within that cognitive faculty. The results indicate very few statistically significant correlations between the spatial tests and performance in the graphical reasoning problems. No significant correlation between the spatial tests and graphical problems exceeded an $r$ value of .5 with correlations ranging from low $(r=.276)$ to moderate $(r=.498)$. More significant correlations occur in Cohort 1 with the MCT than in Cohort 2 where there is only one statistically significant correlation between a graphical task and a psychometric test.

To gain further insight into the problem-solving strategies adopted by the participants', a more in-depth analysis was conducted into the solutions to one of the graphical reasoning problems as discussed earlier. The approach deemed most appropriate was to separate the participants into quartiles based on their scores in the PSVT:R. The PSVT:R was selected as it is a psychometrically sound instrument (Maeda et al. 2013) which is most commonly 
Q1 (a). Shown are the elevation and plan of a dice. Sketch the auxiliary elevation in the direction of arrow A. and a resulting second auxiliary from this in the direction of arrow B indicating the correct spots of the dice.

The development of the dice is provided to assist you.

Hidden detail is not required.

(8 marks)
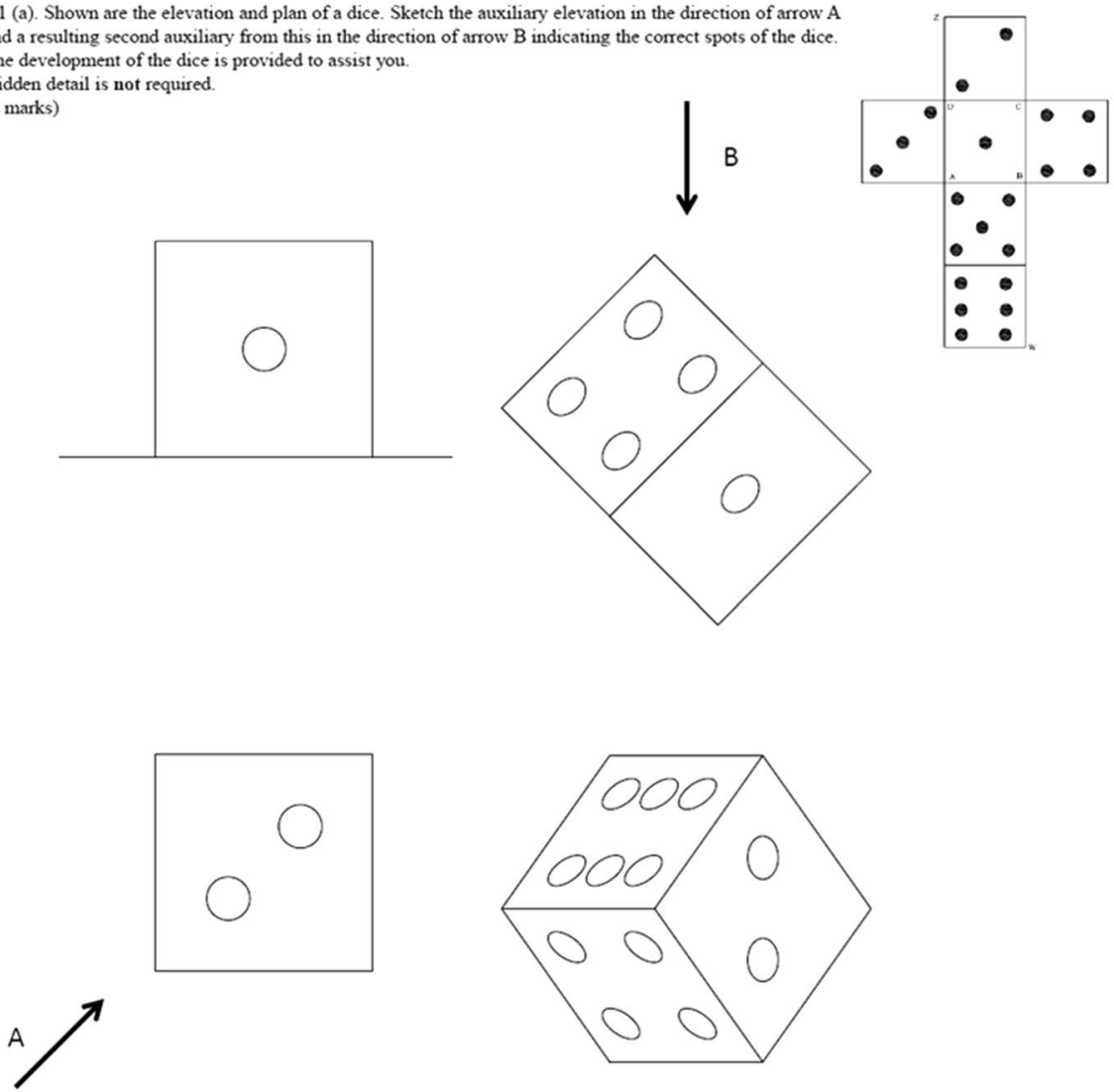

Fig. 2 Solution to the graphical problem given to Cohort 1

Table 1 Cronbach's Alpha scores for psychometric tests utilised in the study

\begin{tabular}{llrlll}
\hline Test & Cohort & $\mathrm{n}$ & Mean (\%) & Std. Deviation & $\begin{array}{l}\text { Cron- } \\
\text { bach's } \\
\text { Alpha }\end{array}$ \\
\hline PSVT:R & 1 & 95 & 76.42 & 14.90 & .801 \\
PSVT:R & 2 & 92 & 77.86 & 13.86 & .761 \\
PSVT:R & 1 and 2 & 187 & 77.13 & 14.39 & .782 \\
MCT & 1 & 88 & 64.86 & 18.42 & .801 \\
CRT & 2 & 91 & 68.83 & 20.64 & .979 \\
PTSOT & 2 & 91 & 86.93 & 11.59 & .886 \\
\hline
\end{tabular}




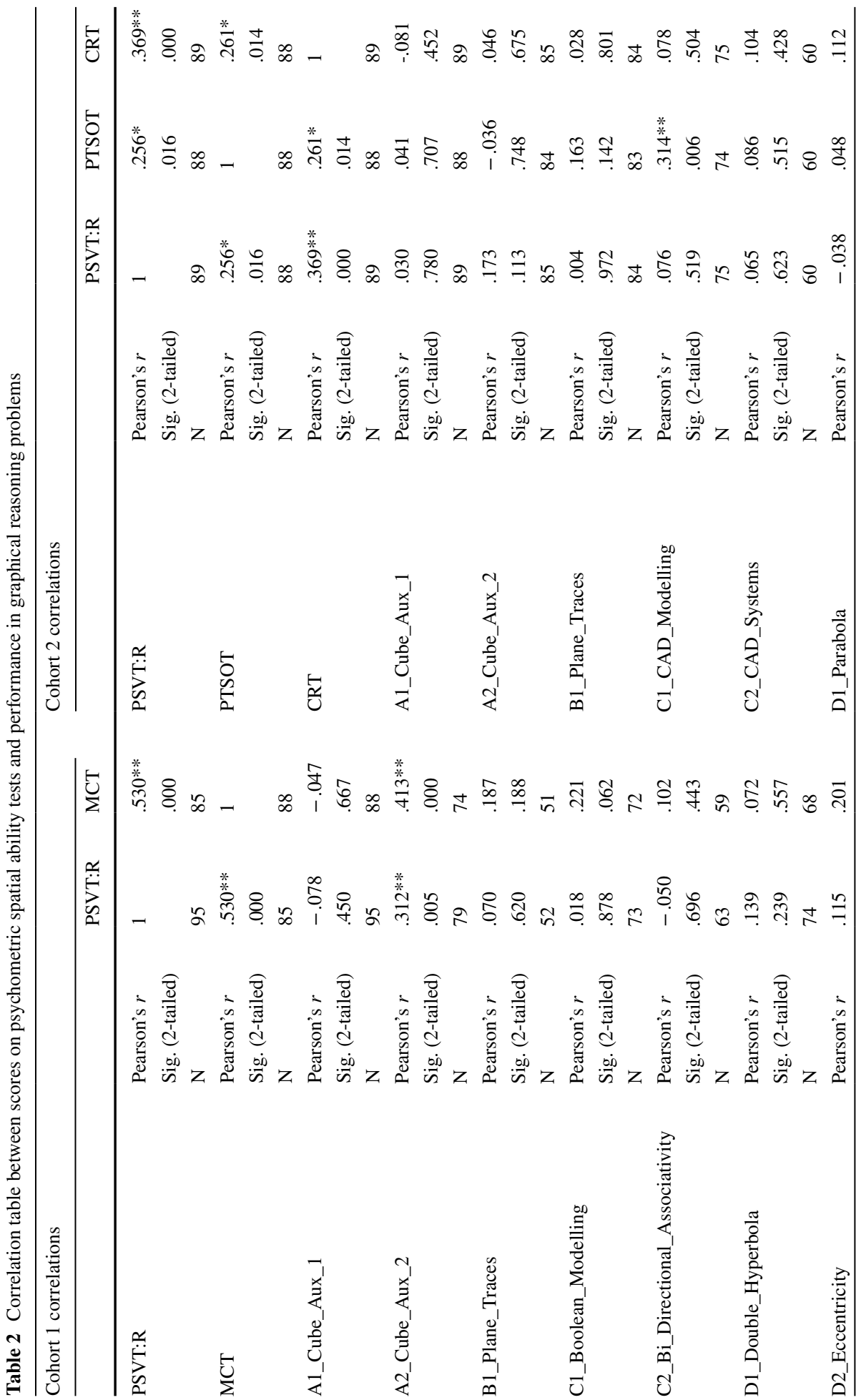




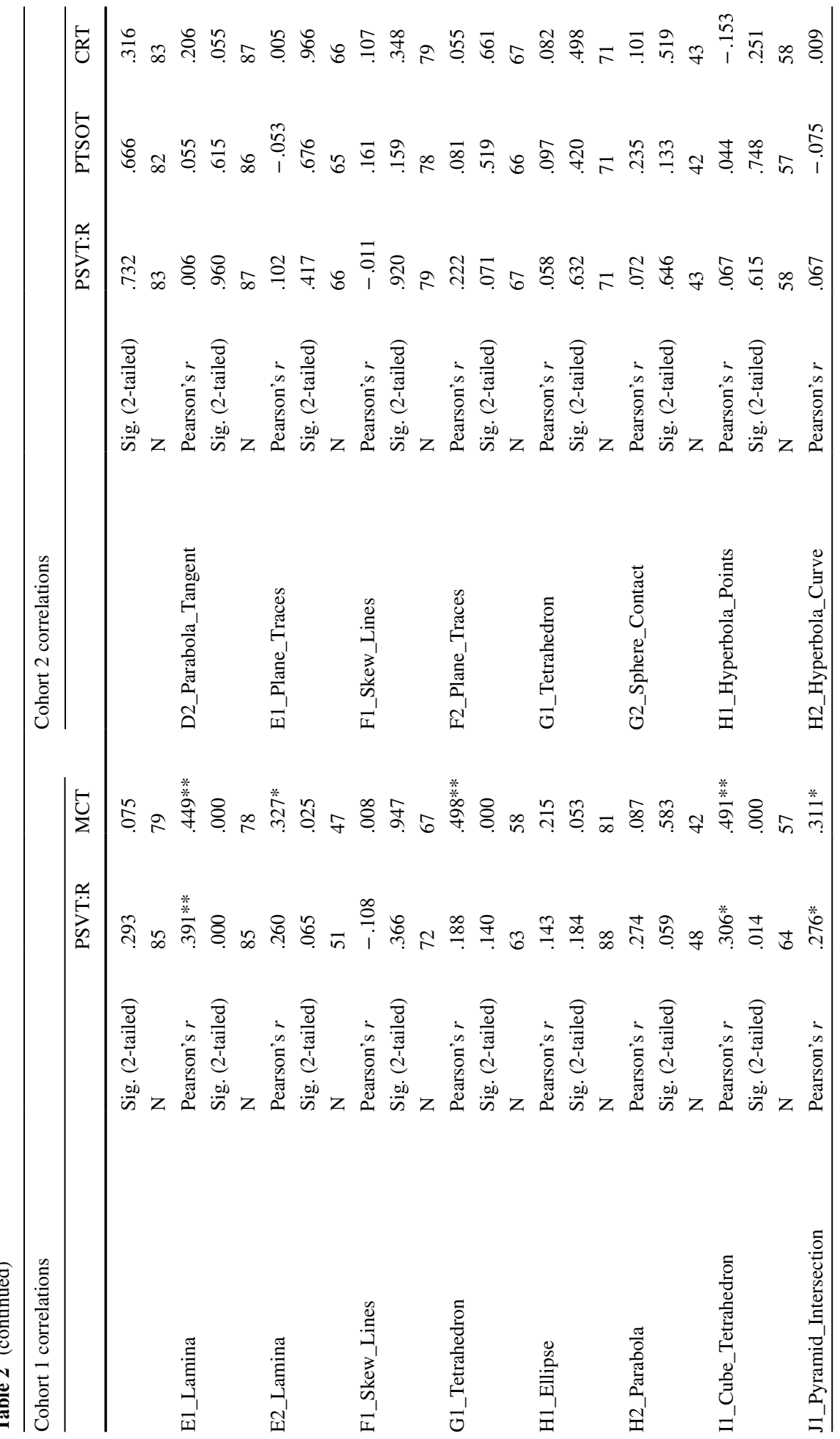




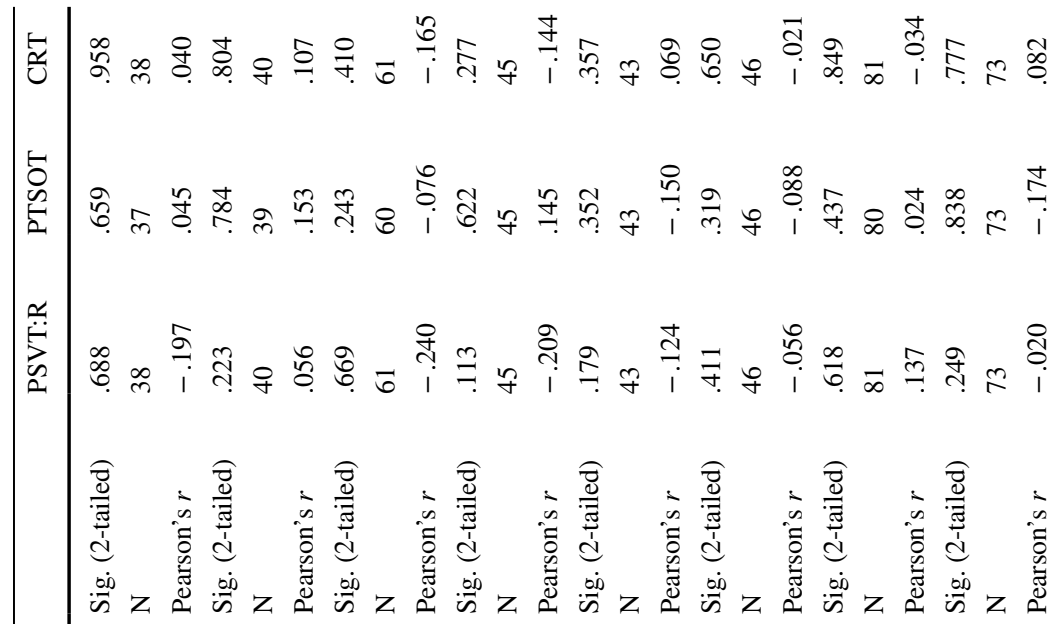
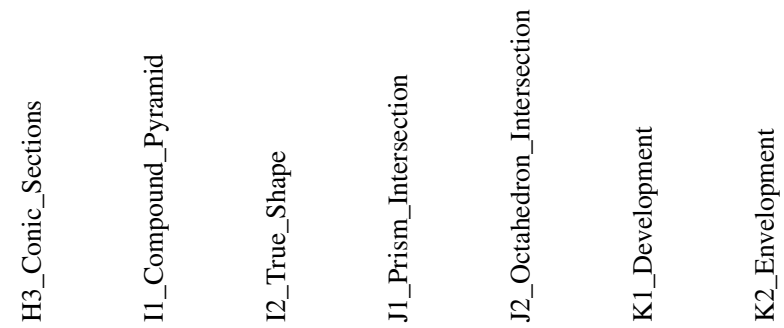

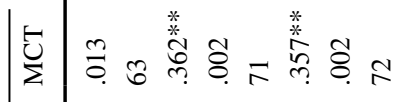

بج

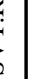

సิ

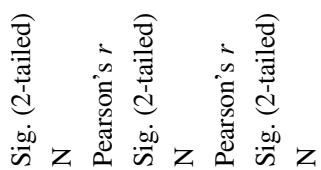




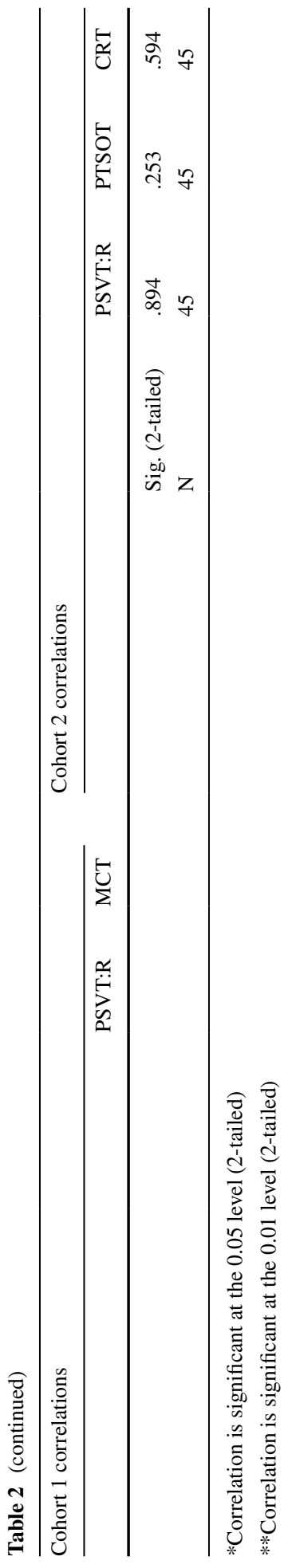

Springer 
used in the identification of correlations between spatial ability and performance in graphical education.

An independent-samples $t$-test was conducted to compare the mean PSVT:R scores between the two cohorts to identify if their results could be combined prior to identifying quartile values for further analysis. There was not a significant difference in the scores for Cohort $1(M=76.42, S D=14.90)$ and Cohort $2(M=77.86, S D=13.89), t(185)=-.684$, $p=.495$. A Chi square test of independence was subsequently performed to examine the relationship between participants being in a specific cohort and being in a specific quartile. The relationship between these variables was not significant, $\chi^{2}(3, \mathrm{~N}=170)=1.02$, $p=.797$. These results indicate no statistical evidence of a relationship between cohorts and quartiles and as such suggest the consideration of all participants as a single cohort was acceptable.

Figure 3 illustrates the results of the analysis of the participants PSVT:R results. The boxplot identifies the quartile values $(\mathrm{Q} 1=70, \mathrm{Q} 2=76.67, \mathrm{Q} 3=90, \mathrm{Q} 4=100)$ and the histogram identifies the frequency of the scores achieved by each student.

After identifying the quartiles associated with performance with the PSVT:R, a oneway ANOVA was conducted to identify if there was any statistically significant variance in performance in the graphical task across each quartile. The result of the ANOVA was that there was no statistically significant difference between performances across the quartiles, $\mathrm{F}(3166)=.605, p=.613$. Despite the lack of statistical significance, the emergent trend (Fig. 4) illustrating that participants with a higher score in the PSVT:R performed better in the graphical task merits further exploration in relation to the strategies utilised within each quartile. While there is only a marginal difference between the 2 nd and 3rd quartiles, the difference is more prominent between the 1st and 4th.

The initial investigation aiming to determine the differences in problem-solving approaches across each quartile involved conducting a correlational analysis between the PSVT:R and performance in the first graphical problem in the battery of graphical tasks. The results are shown in Table 3 and indicate that the statistical significance in the correlations increase as the quartiles progress towards the highest quartile with the only statistically significant correlations being in the 4th quartile. This would further suggest the adoption of a holistic spatial approach as primarily occurring with the
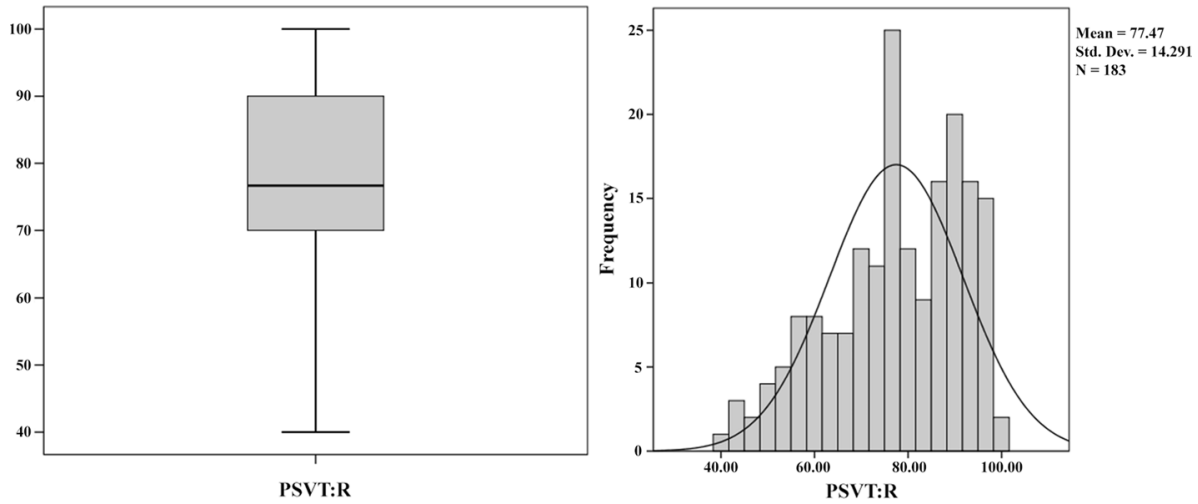

Fig. 3 Boxplot (left) to identify quartile values and histogram (right) to identify frequencies of results in the PSVT:R 


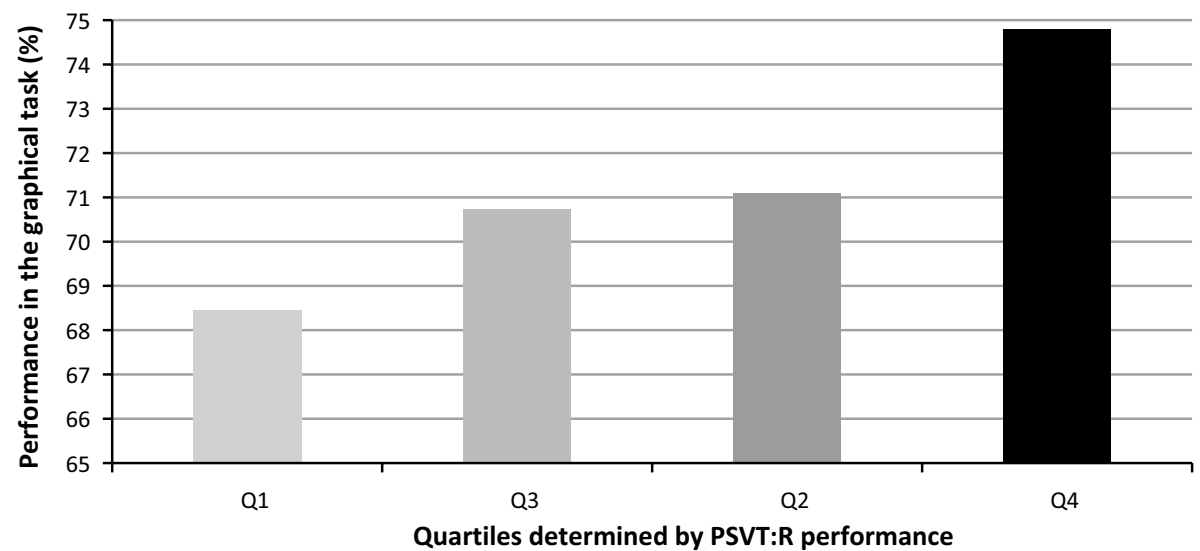

Fig. 4 Performance in the graphical task across all quartiles

Table 3 Correlations between performance in both parts of the graphical reasoning problem and PSVT:R scores for participants in each quartile

\begin{tabular}{lll}
\hline & A1_Cube_Aux_1 & A2_Cube_Aux_2 \\
\hline Q1_PSVT:R & & \\
Pearson's $r$ & -.223 & -0.11 \\
Sig. (2-tailed) & .142 & .944 \\
N & 45 & 45 \\
Q2_PSVT:R & & \\
Pearson's $r$ & .219 & .184 \\
Sig. (2-tailed) & .316 & .401 \\
N & 23 & 23 \\
Q3_PSVT:R & & .186 \\
Pearson's $r$ & .179 & .148 \\
Sig. (2-tailed) & .163 & 62 \\
N & 62 & $.326^{*}$ \\
Q4_PSVT:R & & .017 \\
Pearson's $r$ & $.285^{*}$ & 53 \\
Sig. (2-tailed) & .038 & 53 \\
N & 53 & \\
\hline
\end{tabular}

*Correlation is significant at the 0.05 level (2-tailed)

participants who had a higher capacity in this reasoning style as their performance was more probable to align with their cognitive strengths. This is further supported by the only negative correlations occurring in the 1 st quartile.

The modelling strategies utilised by participants were analysed to support the findings identified through the correlations between spatial and graphical performance. The participant's solutions were coded into methods and modelling techniques which were determined from an inductive observational analysis of their solutions. The solutions illustrated 
Table 4 Descriptive coding of solutions to graphical problems

\begin{tabular}{ll}
\hline Method & Description \\
\hline $\begin{array}{l}\text { Adapted development } \\
\text { Indexing }\end{array}$ & $\begin{array}{l}\text { Adapting the provided development } \\
\text { Indexing the vertices of the cube }\end{array}$ \\
Isometric sketch & $\begin{array}{l}\text { Creating an isometric sketch of the cube } \\
\text { Illustrating additional surface illustrations in the given } \\
\text { orthographic views }\end{array}$ \\
Hidden detail & $\begin{array}{c}\text { Adding hidden detail (not required) in their solutions } \\
\text { Cllustrations converted to numbers }\end{array}$ \\
\hline
\end{tabular}

Table 5 Chi square statistics between quartiles determined by performance in the PSVT:R and frequencies of modelling strategies utilised

\begin{tabular}{lccc}
\hline Method & $\chi^{2}$ & $d f$ & $p$ \\
\hline Adapted development & 2.030 & 3 & .566 \\
Indexing & 2.587 & 3 & .460 \\
Isometric sketch & 7.195 & 3 & .066 \\
Additional orthographic information & 7.030 & 3 & .071 \\
Hidden detail & 5.170 & 3 & .160 \\
Illustrations converted to numbers & .508 & 3 & .917 \\
Total methods used & 14.534 & 9 & .105 \\
\hline
\end{tabular}

varying strategies to solving the problem both in terms of the nature and quantity of the methods adopted. The resulting methods and descriptions are presented in Table 4.

To examine the participants approaches to solving the problems, relationships between each quartile, the nature of modelling techniques utilised and quantity of modelling techniques utilised were analysed using a series of Chi square tests. The results of this analysis are presented in Table 5 and illustrate that no statistically significant observations were observed.

Despite no test identifying any statistical significance the analysis did reveal a number of trends between quartiles and problem-solving approaches. Figure 5 illustrates the number of modelling techniques utilised by participants across quartiles. Of particular interest are the contrasting results observed within the 1st and 4th quartiles as these groups illustrated the most variance in terms of graphical performance. Of all the participants that didn't use any additional modelling techniques, $21.1 \%$ were in the 1 st quartile and $38.6 \%$ were in the 4th quartile. Of all the participants that used a combination of three additional modelling techniques, $50 \%$ were in the 1 st quartile and $16.7 \%$ were in the 4 th quartile. Within these two quartiles, $28.6 \%$ of quartile one didn't utilise any additional modelling techniques while $14.3 \%$ utilised a combination of three and $46.8 \%$ of quartile four didn't use any while $4.3 \%$ used a combination of three. This suggests a higher dependency on externalising techniques by the participants in the 1 st quartile suggesting either a lower efficacy in the cognitive models they created or a lower capacity to interact with these models.

Further analysis focused on the 1st and 4th quartiles to examine the behaviours adopted in the more extreme cases of students pertinent to spatial ability levels and graphical performance. This analysis was conducted to gain additional insight into differences in the selection of modelling techniques. Each solution was coded based on the modelling 


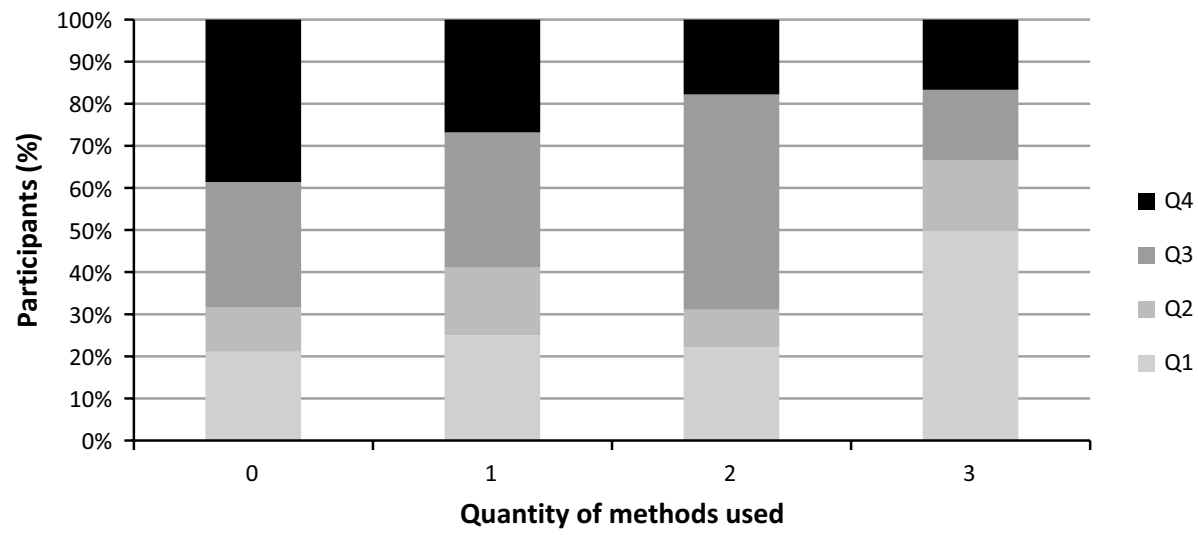

Fig. 5 Number of modelling techniques utilised across quartiles

methods described in Table 4. The frequency by which each occurred was subsequently determined for each quartile. The results of the analysis between the 1st and 4th quartiles are illustrated in Fig. 6. With the exception of adding additional information to the provided orthographic views, each modelling technique was used more in the 1st quartile than in the 4th. The largest variances can be seen in the creation of an isometric sketch [23.8\%] and indexing [11.7\%] and adapting the development [7.6\%]. This is of particular interest as it is arguable as these techniques could most support or circumvention of spatial reasoning by alleviating the need to generate or maintain a vivid cognitive model of the geometry. These results also suggest merit in subsequent related work considering student levels in the imagery spatial factor. This factor is associated with the creation of vivid mental images and has been suggested as contributing to solving geometric problems (Schneider and McGrew 2012).

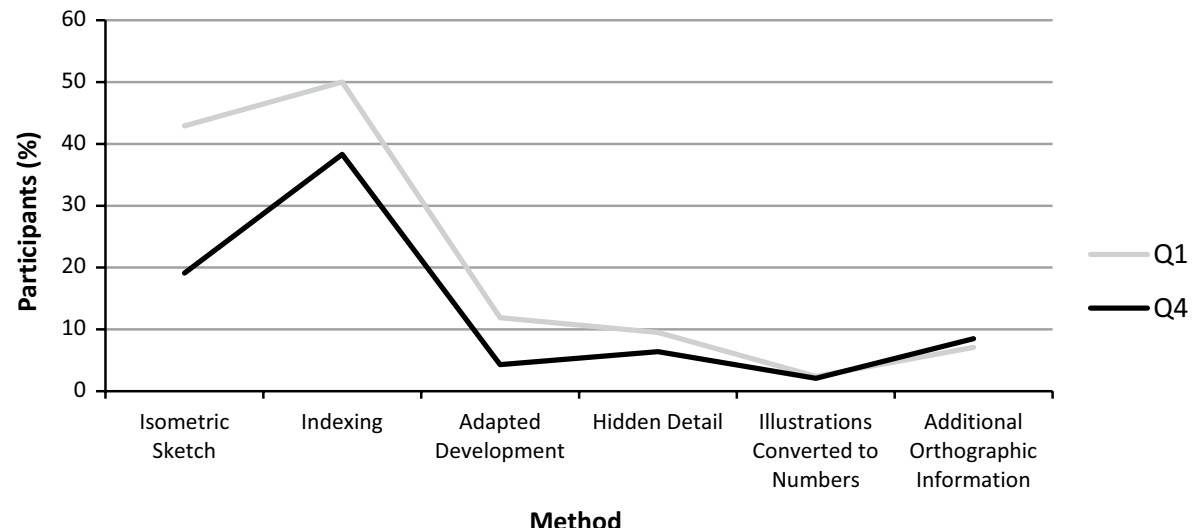

Fig. 6 Modelling techniques utilised by participants in the 1st and 4th quartiles 


\section{Discussion}

In order to contextualise the results relative to the proposed research questions, some limitations of the study should be noted. First, the study cohort was a convenience sample. While the sample was selected and the study was designed to replicate authentic educational provisions, it is important to consider this factor in relation to the generalisability of the results or in future replication studies. Second, the graphical tasks were included as part of a module assessment mechanism. This may have had an influence on the participants' mind-sets and approaches to solving the problems, inducing a number of potential confounding variables which may not exist in a study design where there are fewer implications for the participants relative to task performance. Finally, the graphical tasks were experimental tasks created as part of regular teaching activities. The construct validity of these tasks was not determined.

The first research question asked if students with higher levels of spatial ability utilise this in problem solving. The findings illustrated that in general, having a higher level of spatial ability as measured by the PSVT:R was associated with a higher level of performance in the graphical task examined in this study. The graphical task was typical of problems embodied within graphical education due to its abstract and visual nature. These results align with previous work which has illustrated a correlation between spatial ability and graphical performance (Maeda et al. 2013; Sorby 1999). It is posited that the correlations weren't as strong or statistically significant within this study as there is substantial evidence to suggest the majority of participants encoded the problem externally as well as internally which created an additional variable. However, it is important to note that in order to ensure an authentic educational insight could be derived this couldn't be controlled for. Based on the results of this study, in particular when comparing correlations and approaches to solving the graphical problem between the top and bottom quartile, it appears that students with high levels of spatial ability appear to utilise this while problem solving. In the classical theory of problem solving it is theorised that framing a problem involves building a mental representation of its structure. Based on the findings of this study it is posited that the increased capacity to construct and manipulate a representation of a problem as stemming from an increased level of spatial ability resulted both in the adoption of more holistic spatial approaches and consequential superior performance in the graphical tasks. The increased efficacy in students' cognitive models for those with higher spatial reasoning capacities resulted in a lower number of instances where an intent to externally model emerged.

With respect to the wider educational agenda of STEM education where problem-based learning (PBL) is a pedagogical approach characteristic of the discipline, increasing spatial skills has the potential to contribute to the development of cognitive flexibility and an increased fluidity in problem-solving approaches. Each student exists within a unique bounded rationality while they engage with a problem in that their decisions are governed by time, information and cognitive computational capacities (Gigerenzer and Goldstein 1996). Within an educational problem-solving episode the time is task dependant (typically specified by a teacher or as part of an examination) and the information is situated (based on what the learner knows at the time) but the cognitive capacities are, in some respects, unbounded. Relative to a problem and in some respects, increasing cognitive capacities within students can offer potentially limitless scope for interactions with thoughts and ideas due to the theoretically unbounded realm of the mind which is in direct contrast to limitations which exist in the physical manifestation of a task environment. 
The second research question of this study asked how students with insufficient levels of spatial ability relative to specific graphical problem-solving tasks negotiate problems. Before reflecting on the findings relative to spatial ability, it is necessary to examine the types of cognitive actions which students use when problem solving. Johnston-Wilder and Mason's (2005) model for effective learning (Fig. 7) illustrates these processes to include 'getting-a-sense-of', 'manipulating', and 'articulating'. In this study, where students did not have sufficient levels of spatial ability relative to the demands of the task, the use of external representations can be seen. These helped students to get a sense of the problem and manipulate the information. Similar to how discipline knowledge can alleviate the effects of general cognitive skills in the circumvention of limits hypothesis, external representations in this study appear to have alleviated the need for spatial reasoning or to have supported spatial reasoning in people with lower level of spatial ability.

Building on the second research question, the final research question asked if non-spatial approaches to graphical tasks can give insight into the specific way by which spatial ability facilitates increased performance. Despite not being able to explicitly determine styles of reasoning or an underpinning intent behind the creation of models, there is a clear difference in the graphical approaches embodied within the 1st and 4th quartiles. The modelling strategies utilised are of particular interest as the more prominent techniques implemented by students with lower levels of spatial ability alleviate the need to generate and retain a cognitive model. For example, creating an isometric sketch removes the need to retain the 3-dimensional cube in the working memory allowing more resources to be allocated for other pertinent cognitive actions specific to the problem-solving approach being adopted. Indexing the vertices of the cube also removed the need to store the mental image of the object as each vertex is now easily identifiable and referenced between the orthographic views and the given development allowing for a process of elimination approach to be adopted. It is posited that these approaches stem from the realisation that adopting a spatial approach would not be ecologically rational. This form of auditing or metacognition has been identified as an integral part of the problem-solving process with metacognitive strategies being of particular importance in this instance (Flavell 1979). Considering the

Fig. 7 Model for effective learning (Johnston-Wilder and Mason 2005)

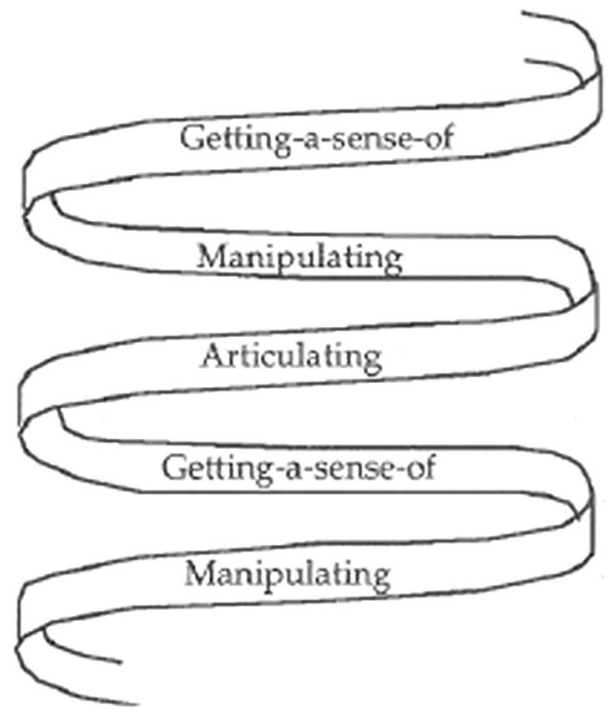


familiarity the participants had with problems of this nature, it is likely that prior metacognitive experiences suggested the adoption of a particular strategy preceding the engagement with the graphical problem. These experiences may have created varying levels of self-efficacy for the participants relative to performance in perceived spatial tasks, seeing students with higher levels of spatial ability predisposed to adopting a spatial approach and those with lower levels more inclined to adopt an analytical approach (Power et al. 2016). Alternatively, at some stage during the problem-solving episode the student may have reached an impasse or "a state of mind in which the problem solver feels that all options have been explored and he or she cannot think of what to do next" (Knoblich et al. 2001, p. 1000). It is posited this scenario is more likely to have occurred with participants in the lower quartiles rather than in higher quartiles due to their lower levels of performance as they did not have the knowledge or tools to progress themselves.

Derived from these hypotheses, a suitable approach to developing problem-solving capacities to better equip students to negotiate problems of this nature would involve increasing their spatial ability level so that they are suitably proficient in the reasoning style which has a greater alignment with success. Significant research has been conducted to create a meaningful intervention to achieve this aim (Sorby 2009; Veurink and Sorby 2011). However, it is imperative that the assumption is not made that such an impasse can only occur in students deemed to have low levels of spatial ability as denoted by performance on the PSVT:R. Spatial ability is widely understood as a second order cognitive factor encompassing multiple 1st order factors (Buckley et al. 2018; Carroll 1993; Schneider and McGrew 2012). The PSVT:R is posited to measure the spatial relations factor. However, in addition to this, multiple other spatial factors are likely to be loading on performance. For graphical problems in particular, the imagery factor, or the generation of a vivid mental image is likely to be inherent, as well as a person's working memory or spatial working memory capacity.

While the results of this study clearly illustrate the influence of spatial ability levels on approaches to solving graphical problems, the examination of memory span is a limitation of this study which should be considered in future research pertaining to this agenda. Considering working memory capacity, the cognitive load produced by the problem is of paramount importance. Cognitive load theory (Sweller 1988) describes the cognitive load imposed by a problem as distinguishable by three types of load; intrinsic, extraneous and germane. Intrinsic load, or load "imposed by the number of information elements and their interactivity" (Paas et al. 2004, p. 2) merits particular consideration in this circumstance. Irrespective of the capacity to mentally manipulate the geometry, if the amount of intrinsic cognitive load imposed on the student by the problem is too great, a holistic spatial approach will be improbable. This could arise from the need to generate an initial cognitive model to storing instances of its manipulation in the working memory. If an impasse of this nature occurs, it may no longer be ecologically rational or even possible for the student to continue with their current strategy. This could invoke the need to progress through a continuum of analytical strategies through the external representation of the problem as a visual model. Creating such a model as a means end strategy, depending on the nature of the model, could be reducing the intrinsic load by compartmentalising the representation of the geometry from its manipulation, alleviating the need to store multiple instances of the model in the working memory or allowing for a purely analytical strategy through the indexing of the geometry. If this is the case, from a pedagogical perspective, in order to best advocate for students in relation to developing flexible problem-solving strategies, a greater understanding is needed pertinent to the selection of reasoning styles and utilisation of modelling techniques as ecologically rational decisions within situated problems. 
Open Access This article is distributed under the terms of the Creative Commons Attribution 4.0 International License (http://creativecommons.org/licenses/by/4.0/), which permits unrestricted use, distribution, and reproduction in any medium, provided you give appropriate credit to the original author(s) and the source, provide a link to the Creative Commons license, and indicate if changes were made.

\section{References}

Alias, M., Black, T., \& Gray, D. (2002). Effect of instructions on spatial visualisation ability in civil engineering students. International Education Journal, 3(1), 1-12.

Archer, B. (1992). As complex as ABC. In P. Roberts, B. Archer, \& K. Baynes (Eds.), Modelling: The language of design. Design: Occasional paper no. 1 (pp. 7-11). Loughborough: Loughborough University.

Barrows, H. (1996). Problem-based learning in medicine and beyond: A brief overview. New Directions for Teaching and Learning, 1996(68), 3-11.

Baynes, K. (2009). Models of change: The impact of "designerly thinking” on people's lives and the environment: Seminar 1... Modelling and intelligence. Design: occasional paper no. 3. Loughborough: Loughborough University.

Baynes, K. (2017). Meaning without words. In E. Norman \& K. Baynes (Eds.), Design epistemology and curriculum planning (pp. 47-63). Leicestershire: Loughborough Design Press.

Bodner, G., \& Guay, R. (1997). The purdue visualization of rotations test. The Chemical Educator, 2(4), $1-17$.

Buckley, J., Seery, N., \& Canty, D. (2018). A heuristic framework of spatial ability: A review and synthesis of spatial factor literature to support its translation into STEM education. Educational Psychology Review. https://doi.org/10.1007/s10648-018-9432-z.

Carroll, J. (1993). Human cognitive abilities: A survey of factor-analytic studies. New York: Cambridge University Press.

CEEB. (1939). Special aptitude test in spatial relations. New York: College Entrance Examination Board.

Chambers, D., \& Reisberg, D. (1985). Can mental images be ambiguous? Journal of Experimental Psychology: Human Perception and Performance, 11(3), 317-328.

Cheng, Y., \& Mix, K. (2014). Spatial training improves children's mathematics ability. Journal of Cognition and Development, 15(1), 2-11.

Cromley, J., Booth, J., Wills, T., Chang, B., Tran, N., Madeja, M., et al. (2017). Relation of spatial skills to calculus proficiency: A brief report. Mathematical Thinking and Learning, 19(1), 55-68.

Danos, X. (2017). Graphicacy and a taxonomy. In E. Norman \& K. Baynes (Eds.), Design epistemology and curriculum planning (pp. 64-84). Leicestershire: Loughborough Design Press.

Dochy, F., Segers, M., \& Van den Bossche, P. (2003). Effects of problem-based learning: A meta-analysis. Learning and Instruction, 13(5), 533-568.

Dow, W. (2006). The need to change pedagogies in science and technology subjects: A European perspective. International Journal of Technology and Design Education, 16(3), 307-321.

Ekstrom, R., French, J., Harman, H., \& Derman, D. (1976). Kit of factor-referenced cognitive tests. Princeton, New Jersey: Educational Testing Service.

Flavell, J. (1979). Metacognition and cognitive monitoring: A new area of cognitive-developmental inquiry. American Psychologist, 34(10), 906-911.

Gallagher, S., Stepien, W., Sher, B., \& Workman, D. (1995). Implementing problem-based learning in science classrooms. School Science and Mathematics, 95(3), 136-146.

Gigerenzer, G., \& Goldstein, D. (1996). Reasoning the fast and frugal way: Models of bounded rationality. Psychological Review, 103(4), 650-669.

Hambrick, D., Libarkin, J., Petcovic, H., Baker, K., Elkins, J., Callahan, C., et al. (2012). A test of the circumvention-of-limits hypothesis in scientific problem solving: The case of geological bedrock mapping. Journal of Experimental Psychology: General, 141(3), 397-403.

Hegarty, M., \& Waller, D. (2004). A dissociation between mental rotation and perspective-taking spatial ability. Intelligence, 32(2), 175-191.

Hmelo-silver, C. (2004). Problem-based learning: What and how do students learn? Educational Research Review, 16(3), 235-266.

Hung, W., Jonassen, D., \& Liu, R. (2008). Problem-based learning. In D. Jonassen (Ed.), Handbook of research on educational communications and technology 3 (pp. 485-506). New York: Macmillan.

Johnston-Wilder, S., \& Mason, J. (2005). Developing thinking in geometry. London: SAGE Publications. 
Jones, S., \& Burnett, G. (2008). Spatial ability and learning to program. Human Technology: An Interdisciplinary Journal on Humans in ICT Environments, 4(1), 47-61.

Kirsh, D. (2009). Problem solving and situated cognition. In P. Robbins \& M. Aydede (Eds.), The Cambridge Handbook of situated cognition (pp. 264-306). Cambridge, Massachusetts: Cambridge University Press.

Knoblich, G., Ohlsson, S., \& Raney, G. (2001). An eye movement study of insight problem solving. Memory \& Cognition, 29(7), 1000-1009.

Koen, B. V. (1985). Definition of the engineering method. Washington, D.C.: American Society for Engineering Education.

Kozhevnikov, M., \& Hegarty, M. (2001). A dissociation between object manipulation spatial ability and spatial orientation ability. Memory \& Cognition, 29(5), 745-756.

Kozhevnikov, M., Motes, M., \& Hegarty, M. (2007). Spatial visualization in physics problem solving. Cognitive Science, 31(4), 549-579.

Kozhevnikov, M., \& Thornton, R. (2006). Real-time data display, spatial visualization ability, and learning force and motion concepts. Journal of Science Education and Technology, 15(1), 111-132.

Larkin, J., \& Simon, H. (1987). Why a diagram is (sometimes) worth ten thousand words. Cognitive Science, 11(1), 65-99.

Larson, G. (1996). Mental rotation of static and dynamic figures. Perception and Psychophysics, 58(1), $153-159$.

Lin, H. (2016). Influence of design training and spatial solution strategies on spatial ability performance. International Journal of Technology and Design Education, 2016(1), 123-131.

Linn, M., \& Petersen, A. (1985). Emergence and characterization of sex differences in spatial ability: A meta-analysis. Child Development, 56(6), 1479-1498.

Lou, S.-J., Shih, R.-C., Diez, C., \& Tseng, K.-H. (2011). The impact of problem-based learning strategies on STEM knowledge integration and attitudes: An exploratory study among female Taiwanese senior high school students. International Journal of Technology and Design Education, 21(2), 195-215.

Loyens, S., Kirschner, P., \& Paas, F. (2011). Problem-based learning. In S. Graham, A. Bus, S. Major, \& L. Swanson (Eds.), APA educational psychology handbook: Application of learning and teaching (Vol. 3, pp. 403-425). Washington, DC: American Psychological Association.

Maeda, Y., Yoon, S. Y., Kim-Kang, G., \& Imbrie, P. K. (2013). Psychometric properties of the revised PSVT: R for measuring first year engineering students' spatial ability. International Journal of Engineering Education, 29(3), 763-776.

Marunic, G., \& Glazar, V. (2013). Spatial ability through engineering graphics education. International Journal of Technology and Design Education, 23(3), 703-715.

Miller, A. (1984). Imagery in scientific thought: Creating 20th century physics. Boston: Birkhquser.

Paas, F., Renkl, A., \& Sweller, J. (2004). Cognitive load theory: Instructional implications of the interaction between information structures and cognitive architecture. Instructional Science, 32(1), 1-8.

Perrenet, J., Bouhuijs, P., \& Smits, J. (2000). The suitability of problem-based learning for engineering education: Theory and practice. Teaching in Higher Education, 5(3), 345-358.

Pink, D. (2005). A whole new mind: Why right-brainers will rule the future. New York: Penguin Group (USA) Inc.

Pittalis, M., \& Christou, C. (2010). Types of reasoning in 3D geometry thinking and their relation with spatial ability. Educational Studies in Mathematics, 75(2), 191-212.

Power, J., Buckley, J., \& Seery, N. (2016). Visualizing success: Investigating the relationship between ability and self-efficacy in the domain of visual processing. In L. Sun, H. Steinhauer \& D. Lane (Eds.), ASEE engineering design graphics division 70th mid-year conference (pp. 73-79). Daytona Beach, Florida: EDGD.

Ramey, K., \& Uttal, D. (2017). Making sense of space: Distributed spatial sensemaking in a middle school summer engineering camp. Journal of the Learning Sciences, 26(2), 277-319.

Rochford, K. (1985). Spatial learning disabilities and underachievement among university anatomy students. Medical Education, 19(1), 13-26.

Russell-Gebbett, J. (1985). Skills and strategies-pupils' approaches to three-dimensional problems in biology. Journal of Biological Education, 19(4), 293-298.

Savery, J., \& Duffy, T. (2001). Problem based learning: An instructional model and its constructivist framework. Bloomington, Indiana: Indiana University.

Schneider, J., \& McGrew, K. (2012). The Cattell-Horn-Carroll model of intelligence. In D. Flanagan \& P. Harrison (Eds.), Contemporary intellectual assessment: Theories, tests, and issues (3rd ed., pp. 99-144). New York: Guilford Press.

Seery, N. (2017). Modelling as a form of critique. In P. J. Williams \& K. Stables (Eds.), Critique in design and technology education (pp. 255-273). Singapore: Springer. 
Seery, N., Lynch, R., \& Dunbar, R. (2011). A review of the nature, provision and progression of graphical education in Ireland. In E. Norman \& N. Seery (Eds.), IDATER online conference: Graphicacy and modelling (pp. 51-68). Loughborough: Design Education Research Group, Loughborough Design School.

Shea, D., Lubinski, D., \& Benbow, C. (2001). Importance of assessing spatial ability in intellectually talented young adolescents: A 20-year longitudinal study. Journal of Educational Psychology, 93(3), 604-614.

Small, M., \& Morton, M. (1983). Research in college science teaching: Spatial visualization training improves performance in organic chemistry. Journal of College Science Teaching, 13(1), 41-43.

Sorby, S. (1999). Developing 3-D spatial visualization skills. Engineering Design Graphics Journal, 63(2), 21-32.

Sorby, S. (2009). Educational research in developing 3-D spatial skills for engineering students. International Journal of Science Education, 31(3), 459-480.

Sorby, S., Casey, B., Veurink, N., \& Dulaney, A. (2013). The role of spatial training in improving spatial and calculus performance in engineering students. Learning and Individual Differences, 26(1), 20-29.

Stieff, M. (2007). Mental rotation and diagrammatic reasoning in science. Learning and Instruction, 17(2), 219-234.

Suzuki, K., Wakita, S., \& Nagano, S. (1990). Improvement of spatial ability through descriptive geometry education. Journal of Graphic Science of Japan, 24(1), 21-28.

Sweller, J. (1988). Cognitive load during problem solving: Effects on learning. Cognitive Science, 12(2), 257-285.

Uttal, D., \& Cohen, C. (2012). Spatial thinking and STEM education: When, why, and how? Psychology of Learning and Motivation, 57(1), 147-181.

Veurink, N., \& Sorby, S. (2011). Raising the bar? Longitudinal study to determine which students would most benefit from spatial training. In 118th annual american society for engineering education conference. Vancouver, British Columbia: American Society for Engineering Education.

Wai, J., Lubinski, D., \& Benbow, C. (2009). Spatial ability for STEM domains: Aligning over 50 years of cumulative psychological knowledge solidifies its importance. Journal of Educational Psychology, 101(4), 817-835.

Wang, Y., \& Chiew, V. (2010). On the cognitive process of human problem solving. Cognitive Systems Research, 11(1), 81-92.

Wang, Y., Wang, Y., Patel, S., \& Patel, D. (2006). A layered reference model of the brain (LRMB). IEEE Transactions on Systems, Man, and Cybernetics, 36(2), 124-133.

Webb, R., Lubinski, D., \& Benbow, C. (2007). Spatial ability: A neglected dimension in talent searches for intellectually precocious youth. Journal of Educational Psychology, 99(2), 397-420.

Williams, P. J., Iglesias, J., \& Barak, M. (2008). Problem based learning: Application to technology education in three countries. International Journal of Technology and Design Education, 18(4), 319-335.

Williams, A., \& Williams, P. J. (1997). Problem-based learning: An appropriate methodology for technology education. Research in Science \& Technological Education, 15(1), 91-103.

Wu, H.-K., \& Shah, P. (2004). Exploring visuospatial thinking in chemistry learning. Science Education, $88(3), 465-492$. 